\title{
The challenges of delivering good practice for volunteer youth workers in youth development organisations
}

\author{
Rod Adam \\ rodadam72@gmail.com
}

\begin{abstract}
Recent research has shown that programs provided by youth development organisations are of considerable benefit to those young people who engage with the aims and activities of such programs. These programs (e.g. Scouts, Guides, Boys' and Girls' Brigades, Surf Lifesaving) are generally provided and run by adult volunteers. This article seeks to explore the main issues for volunteers with regard to implementing these programs, including the reasons why people volunteer in the first place, what community support and resourcing are available and the difficulties of running a program with too few volunteers. The main limiting factor in the success of these programs is the available volunteers, their individual skill levels, the time they have to give and whether they feel the return for their efforts is worthwhile. Community and parental recognition is also a significant factor in their satisfaction and longevity. Volunteers generally gain satisfaction and motivation through a mix of self-worth gained through community service and being able to pass on the program and ethos of their particular organisation. How long a volunteer serves as a leader is closely connected with their satisfaction level. The author's many years of experience at local and state level provides insight into the recruitment and retention of volunteer leaders and their important role in continuing to provide youth programs at the local level.
\end{abstract}

\section{Introduction}

Youth development organisations like Scouts, Guides, Boys' and Girls' Brigades and Surf Lifesaving rely very much, if not exclusively, on adult volunteers to implement their programs. While recent research (Seymour 2015; see also Introduction to this special issue) shows that these types of programs are of considerable benefit to those young people who participate in them, without the adult volunteers these organisations could not operate, no matter how worthwhile their programs are. In this article, I will discuss the main issues that influence the recruitment and retention of adult volunteers and the resultant viability and sustainability of youth development organisations to continue to provide programs. In my experience, finding long-term committed leaders is a much greater challenge for these organisations than recruitment of youth members. 
This article is based largely on my experience in program delivery and development, and leader training, in the Boys' Brigade (BB) in Queensland, Australia and the Pacific. BB is an awards-based program that challenges, rewards and encourages boys of all backgrounds through age-appropriate outdoor and indoor, sporting and physical exercise, and technologically focused developmental activities (Boys Brigade 2017a). The program aims to support boys to develop life, social, leadership and physical skills within a Christian framework. BB Queensland is a state-based, uniformed organisation with both national and international links (Boys Brigade 2017b, 2017c). The local group (company) is attached to a local church, which approves the volunteer leaders - usually a mix of younger and older adults. There are three age groups: Anchors, aged five to seven years; Juniors, aged eight to eleven years; and Seniors, aged twelve to eighteen years (Boys Brigade 2017c). Although meetings are usually held on week nights and vary from one to two and a half hours in duration, depending on the age group, BB groups sometimes participate in or host weekend activities such as camps or community service projects (Boys Brigade 2017d, 2017e).

I also draw on my extensive network experience with other organisations through the Queensland Youth Alliance. The Queensland Youth Alliance (QYA), established in 1996, brings together a diverse range of Queensland's major youth development organisations (QYA 2017a). Currently, there are fourteen member organisations ranging from Scouts, Guides, and Boys' and Girls' Brigades to Surf Lifesaving, Army Cadets and the YMCA (QYA 2017a, 2017b). The QYA provides a forum in which these organisations can work together to develop and promote a better understanding about the work they do, develop cooperation, collaborate, exchange ideas and network (QYA 2017a). QYA also provides a united voice with which these organisations communicate with relevant government departments regarding youth issues, child safety requirements and outdoor recreational facilities.

\section{Types of organisations}

Adults volunteer to serve in a wide range of youth organisations so it is first useful to consider the aims of those organisations and their place in contemporary society. Understanding these organisational aims to explain why adult leaders are willing to make a commitment of time and effort to make the programs happen. Youth development organisations such as those listed above generally share a common core of aims such as life skills, team-building, social skills, personal integrity, community service, leadership development, recognition of achievement and commitment to the local group. The different organisations then have distinctive activities that distinguish them from the others, such as lifesaving, first-aid and outdoor skills, with distinctive uniforms and distinctive values. Accountability is usually to a state or national body. BB is also accountable to the sponsoring local church.

\section{Why volunteer?}

So why do young and older adults volunteer to be leaders? In my experience volunteering in $\mathrm{BB}$, I have found this to be a complex question. In $\mathrm{BB}$, leaders volunteer one night a week and a number of days on weekends throughout the year, including some whole weekends, for camps and trips away, which may mean time away from their own families. For many, there will also be a monetary cost 
for uniforms, petrol and equipment. Because it costs the participating adult to volunteer, there must be a commensurate pay-off in order for them to continue to volunteer. Fundraising is another challenge for the volunteer, in order to keep member fees as low as possible so they will not be a barrier to low-income families. Sausage sizzles, cake stalls and car washes take up valuable time for the volunteer, on top of their other commitments.

A number of leaders are parents of members; they have often had some experience of being a member themselves and want their children to enjoy the same experience. It is my experience, however, that the majority of non-parent leaders volunteer for other reasons. The main reason is that they value the aims of youth development programs to produce young adults who will contribute to a better society. My observations at events and in conversations are that this is a great source of personal satisfaction. Other reasons include giving the volunteer a place of their own significance, camaraderie with other leaders and ensuring the continuance of the particular organisation. Leaders in faith-based organisations will also have some interest in faith development, although for BB this is generally not a requirement of membership or participation.

Of course, if the expectations of volunteers are not being fulfilled, they will likely not continue to volunteer and will cease their involvement. Governing bodies of youth organisations should never ignore this fact.

\section{The search for 'good practice'}

When a leader is part of a program that continues to bring them satisfaction, their commitment is likely to continue. That is, the payoff is worth the cost. So, in order to assess the effectiveness of programs, volunteer leaders need to have tools to evaluate whether the outcomes of their programs are really fulfilling the aims of the organisation and best recognised practice. The publication of Good Practice Principles for Youth Development Organisations (Seymour 2012) has been very useful in giving organisations a framework for evaluating whether their stated aims are the best they could be and whether programs at the local level are meeting these aims. There can be a tendency for volunteer leaders to concentrate on the activities themselves rather than the role that the activity has in developing the young person. The leader needs to understand the 'why' of the activity as well as the 'how'. Leader-training courses need to ensure a focus on 'good practice' principles (the above publication is very useful for this) so that volunteers are more likely to experience the payoff mentioned earlier and stay involved in the organisation for a long time.

\section{Community support}

Another aspect of volunteer satisfaction is the level of support received from the community. If a leader feels that the local community, and particularly members' parents, support the particular organisation, then they will feel appreciated and see their time and effort as worthwhile. Many groups become well known in their local community for the positive impact they are having on their members, and such feedback to leaders will add to the payoff effect. If the volunteer feels that their efforts are actually adding to the social capacity of the local community, that will be rewarding in itself. 


\section{Member support of leaders}

When members and past members express their thanks for what the leader has done for them, that is a great boost to satisfaction and payoff. As a long-time BB leader, I get a great sense of worthwhileness when a former member expresses in later life what their time in BB meant to them. Recently, a man of fifty-four stopped me and introduced himself as a former member in his teens. He said that only recently he had been thinking how much he still did that he had learned in Boys' Brigade, and how much he valued it.

\section{Personal integrity}

Another challenge for the volunteer leader is their own personal integrity. In order to have members develop the qualities of life success, team player, social skills, personal integrity, community service, leadership and commitment - which are the aims of all youth development organisations - the volunteer will be expected to demonstrate these in their own life and set an example to the young members. If they are unable to do this, their effectiveness as a leader will be greatly reduced. Youth development programs are structured to encourage the development of these life skills and values in members, and the members will learn them from their leaders. In this context, leadership is as much being as doing.

\section{Succession planning}

Leadership development generally is an important part of youth development programs, and completion of levels of leadership training is usually recognised in the program structure. There are two significant outcomes resulting from leadership training in youth organisations. The first is to provide leadership experiences and skills to build confidence that will be useful for the participant in later life in the family, at work and in the community. The second outcome from the organisation's viewpoint is that developing young leaders is vital for the future of that organisation, in providing volunteer leaders to continue to run the organisation at the local level. In BB, a young man can enrol as a leader the year he turns 19, which enables him to have continued involvement in BB activities and friendships while at the same time being mentored by older leaders while he completes his formal leader training and child safety requirements. My observation is that the majority of leaders in charge of local youth programs across all organisations are former members. Leaders of local groups should always have in mind who is next to take over when they leave. In my experience, not having a succession plan in place when the leader in charge resigns is the main reason why local groups cease to operate.

\section{Accreditation}

A final challenge for voluntary youth leadership is the relatively recent requirement for accreditation and qualifications for many of the traditional activities of youth development organisations. For example, the BB insurer has supplied a comprehensive list of approved activities and the qualifications required to run them. Organisations that have a broad-based program of development, which once would have done canoeing once or twice a year, bushwalking a couple of times, surfing, abseiling once a year, some elementary gymnastics, an archery day and a bike ride 
now have to have a leader with formal qualifications in order to run the activity. While this is understandable from a risk-reduction point of view, it has meant that the requirements for a volunteer leader have increased considerably, both in time and cost. For example, a volunteer with considerable canoeing experience still needs an instructor's certificate - often self-funded - before taking boys out on the water.

\section{Conclusion}

Member numbers in traditional youth development organisations have decreased considerably over the last twenty-five years. This decrease is matched by a corresponding decrease in the numbers of volunteer leaders. While the personal development aims of these organisations remain much the same but within a contemporary context the delivery of their programs is restricted by the lack of volunteer leaders to operate the program at the local level. If these organisations are to continue to fulfil their valuable role in providing personal development for youth, then their governing bodies will need to make volunteer recruitment as accessible and attractive as possible, and provide quality training to assist volunteers in finding satisfaction in their service.

\section{References}

Boys Brigade 2017a. 'Boys Brigade in Queensland', http://boys.brigadeaustralia.org/qld. — 2017b. 'Uniform', http://boys.brigadeaustralia.org/about/uniform.

— 2017c. 'Fun, adventure, challenge', http://boys.brigadeaustralia.org/about/q-a.

— 2017d. 'Pan Australia camps', http://boys.brigadeaustralia.org/about/panaustralian-camps.

— 2017e. 'Glengarry Education Centre', http://boys.brigadeaustralia.org/glengarry.

Queensland Youth Alliance (QYA) 2017a. 'About the QYA', http://qya.org.au/ about-the-qya-new.

— 2017b. 'Member organisations', http://qya.org.au.

Seymour K. 2012. Good practice principles for youth development organisations, 2nd ed. Brisbane: Key Centre for Ethics, Law, Justice and Governance, Griffith University.

2015. 'Deficits or strengths? Re-conceptualising youth development program practice'. Unpublished PhD thesis, Griffith University, Brisbane. 